\title{
DEVELOPMENT OF LARGE STONE ASPHALT MIXTURES IN RIYADH
}

\author{
Mahmoud El-Shourbagy \\ Faculty of Engineering. \\ Mansoura University \\ Mahmoudshourbagy@Yahoo.com
}

\author{
Saad El-Hamrawy \\ Faculty of Engineering., \\ Minoufiya University \\ SHamrawy@Yahoo.com
}

\begin{abstract}
Premature rutting of heavy duty asphalt pavements has been increasingly experienced in recent years primarily due to high pressure truck tires and increased wheel loads. Many asphalt technologists believe that the use of large size stone (maximum size of more than one inch) in the binder and base courses will minimize or eliminate the rutting of heavy duty pavements.

This research describes a development of new asphalt mix design procedure which is a better indicator of road performance in Riyadh. The Marshall method has served well over the years but as wheel loads and tire pressures increase, and as temperature is high, there was a need for an update of mix design procedures.

This new method allowed the incorporation of aggregate size larger than $25 \mathrm{~mm}$, and the use of vibratory compaction apparatus with 6.0 inch mould size diameter.

Results from the mix design study indicated that when compared to the conventional mix characteristics, the introduction of larger stone to the asphalt mixture improves its properties considerably.

الغرض من هذا البحث هو ثطوير خليط أسفلثى جديد يوفر أففل مؤشر لأداء الططريق في مدينة اللرياض بالمملكة

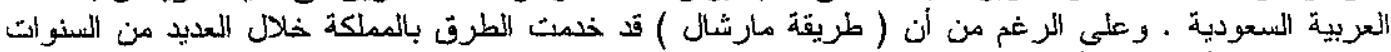

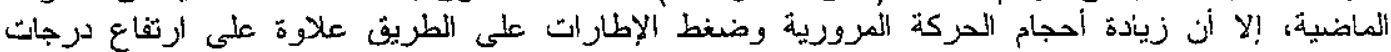

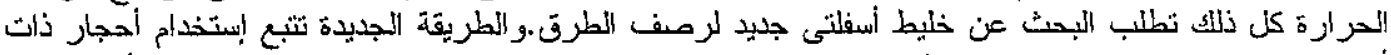

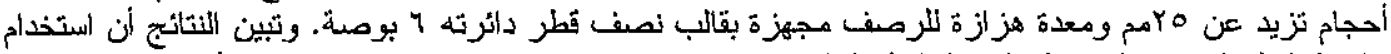

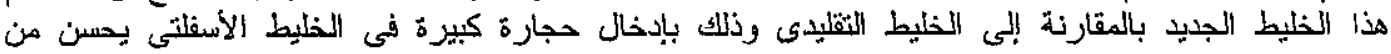
خصائه ومميزات الخليط بدرجات كبيرة المقارئ.
\end{abstract}

Keywords Marshall mix Design, Large Stone, Vibration, Indirect Tensile Strength, and Fatigue Prediction.

\section{INTRODUCTION}

During the last few years, there has been considerable increase in volume of heavy trucks with large axle loads and high tire pressure. The Actual maximum single axle load can reach 25 to 30 tons [1], and the total predicted number of standard single axle load applications for trucks is about 150 to 160 PSI $[2,3]$.

On the other hand, high temperature weather prevails in Riyadh for most time of the year. The ambient temperature is about 40 to $45^{\circ} \mathrm{C}$ for few months of the year, and measured temperature of pavement surface is about $80-85^{\circ} \mathrm{C}$.
Although, the structural design of pavement is quite satisfactory, after some of the highways were opened to traffic, they suffered from different types of distress such as fatigue cracking, bleeding and rutting. The method of asphalt mix design, which has been used for long time in Riyadh, is Marshall Method, which is currently used by many agencies all over the World

This method of mix design has many shortcomings such as:

- The maximum size of aggregate is limited to 1.0 inch. 
- The method of compacting Marshall specimen is by impact, which is different from the one actually taking place in field by rollers.

- The thickness of Marshall sample is almost constant, and it does not take into consideration the different layers thickness in the field.

- The aggregate orientation in Marshall mould is different from that actually occurring in the field.

- Marshall Mix design method does not take into consideration resistance of mix to many types of distress such as fatigue and rutting. Stability and flow are used which are measured at $60^{\circ} \mathrm{C}$. Therefore, the method ignores the effect of temperature.

In current roads contracts specification in Riyadh, one of the following maximum aggregate size and method of mix design is normally specified.

1. $4.0 \mathrm{~mm}$ aggregate maximum size, with Marshall method of mix design.

2. $5.0 \mathrm{~mm}$ aggregate maximum size, with Marshall method of mix design, but with substituting aggregate larger than $25.4 \mathrm{~mm}$ with an equivalent weight of $19.0-25.4 \mathrm{~mm}$.

3. $37.5 \mathrm{~mm}$ aggregate maximum size, with Marshall method of mix design, without substitution.

Binder and aggregate characteristics are believed to affect the rutting performance of asphalt pavements. Experience shows that stiff binders with large aggregates typically are more resistance to rutting than mixes containing finer aggregates and higher binder contents [4].

A lot of problems were faced, during construction, one of which is the large difference between in-situ density and Marshall density and high variation in daily Marshall densities due to presence of large size aggregate. It is believed, that using this large aggregate is the correct step in the right direction, but a proper method of mix design shall be used [5].

In this paper, a new method of mix design was developed, which would suit available materials and local conditions. In this proposed method, most disadvantages of conventional methods were avoided and the new mix has better performance under heavy traffic and high temperature.

\section{MATERIAL CHARACTERIZATION}

\section{2-1-Asphalt Cement}

One type of asphalt cement was selected for use in the study: AC 60/70 penetration grade supplied by Saudi Bitumen Supply Company.
The asphalt cement was subjected to a series of standard laboratory tests to determine its physical properties. Results of these tests are shown in Table 1.

\section{2-2-Aggregate Selection}

The aggregate sizes used in this paper were $37.5-$ $28 \mathrm{~mm}, 22-12 \mathrm{~mm}, 12-5 \mathrm{~mm}$ and $5-0 \mathrm{~mm}$. Results of the aggregate tests are shown in Table 2.

Table 1: Properties of Asphalt Cement

\begin{tabular}{|c|c|}
\hline Test & Result \\
\hline Penetration at $25^{\circ} \mathrm{C}$ & 62 \\
\hline Viscosity at $135^{\circ} \mathrm{C}(\mathrm{Cst})$ & 460 \\
\hline $\begin{array}{c}\text { Ring and Ball Softening } \\
\text { Point }\left({ }^{\circ} \mathrm{C}\right)\end{array}$ & 51 \\
\hline Specific Gravity & 1.03 \\
\hline
\end{tabular}

\section{EXPERIMENTAL WORK}

The main objective of this research was to develop a new mix design procedure which is better indicator of road performance than existing method. In order to achieve this objective, the following laboratory work was conducted.

Relative density of filler $=2.918$

\subsection{Marshall Method}

Two mixtures were prepared using Marshall method of mix design as detailed in Asphalt Institute Manual MS-2.

The aggregate grading of these two mixes is as follows:

\begin{tabular}{|c|c|c|c|}
\hline $\begin{array}{c}\text { Sieve Size } \\
(\mathrm{mm})\end{array}$ & $\begin{array}{c}\text { Grading } \\
\text { LSA-3 }\end{array}$ & $\begin{array}{c}\text { Grading } \\
\text { LSA - 8 }\end{array}$ & $\begin{array}{c}\text { Specificat } \\
\text { ion Limits } \\
\text { BS 4987 }\end{array}$ \\
\hline 50 & 100 & 100 & \\
37.5 & 100 & 100 & 100 \\
28 & 83 & 78 & $95-100$ \\
14 & 65 & 65 & $70-94$ \\
6.3 & 49 & 49 & $56-76$ \\
3.35 & 41 & 41 & $44-60$ \\
0.300 & 13 & 13 & $32-46$ \\
0.075 & 3 & 3 & $7-21$ \\
\hline
\end{tabular}


M. El-Shourbagy and S. El-Hamrawy, "Development Of Large Stone Asphalt Mixtures In Riyadh"

Table 2: Aggregate Properties

\begin{tabular}{|c|c|c|c|c|}
\hline & \multicolumn{4}{|c|}{ Aggregate Size $(\mathrm{mm})$} \\
\hline & $37.5-28$ & $22-12$ & $12-5$ & $5-0$ \\
\hline Sand Equivalent & - & - & - & 791 \\
\hline Apparent Specific Gravity & 2.957 & 2.976 & 2.977 & $2.970^{*}$ \\
\hline Cross Specific Gravity & 2.926 & 2.952 & 2.951 & 2.921 \\
\hline Water Absorption & 0.351 & 0.27 & 0.301 & 0.502 \\
\hline Abrasion & 0.131 & 141 & 141 & - \\
\hline Elongation Index & 161 & 251 & 291 & - \\
\hline $\begin{array}{l}\text { Aggregate grading passing } \\
\text { following sizes: } \\
50 \mathrm{~mm} \\
37.5 \mathrm{~mm} \\
28 \mathrm{~mm} \\
14 \mathrm{~mm} \\
6.3 \mathrm{~mm} \\
3.35 \mathrm{~mm} \\
0.300 \mathrm{~mm} \\
0.075 \mathrm{~mm}\end{array}$ & $\begin{array}{l}100 \\
41.1\end{array}$ & $\begin{array}{l}100 \\
44.4\end{array}$ & $\begin{array}{l}1 \\
0 \\
0 \\
33.1 \\
0.8\end{array}$ & $\begin{array}{c}100 \\
93 \\
28 \\
9.5\end{array}$ \\
\hline
\end{tabular}

* Specific Gravity values were determined on fine aggregate without filler.

Another two mixtures were prepared using the same gradation as (LSA - 3 \& LSA - 8) but with substituting the aggregate larger than $25.4 \mathrm{~mm}$ with the equivalent weight of $19-25.4 \mathrm{~mm}$ (LSA -4 and LSA - 12) respectively. Figure (1) shows the aggregate gradation of all these mixes together with specification limits.

The optimum binder content was determined for all these mixtures and the corresponding properties are shown in Table (3). Marshall specimens were prepared at optimum binder content for the above mixes and then tested for the indirect tensile strength and fatigue prediction.

\subsubsection{Development of New Mix Design Procedure} a) Background

Aggregate with maximum size larger than 1.0 inch can't be used in the 4.0 inch mould. Many agencies simply aggregate quality, aggregate grading and two design asphalt cement contents based on experience. These recipes - type methods are difficult to adjust according to changes in traffic and environment.

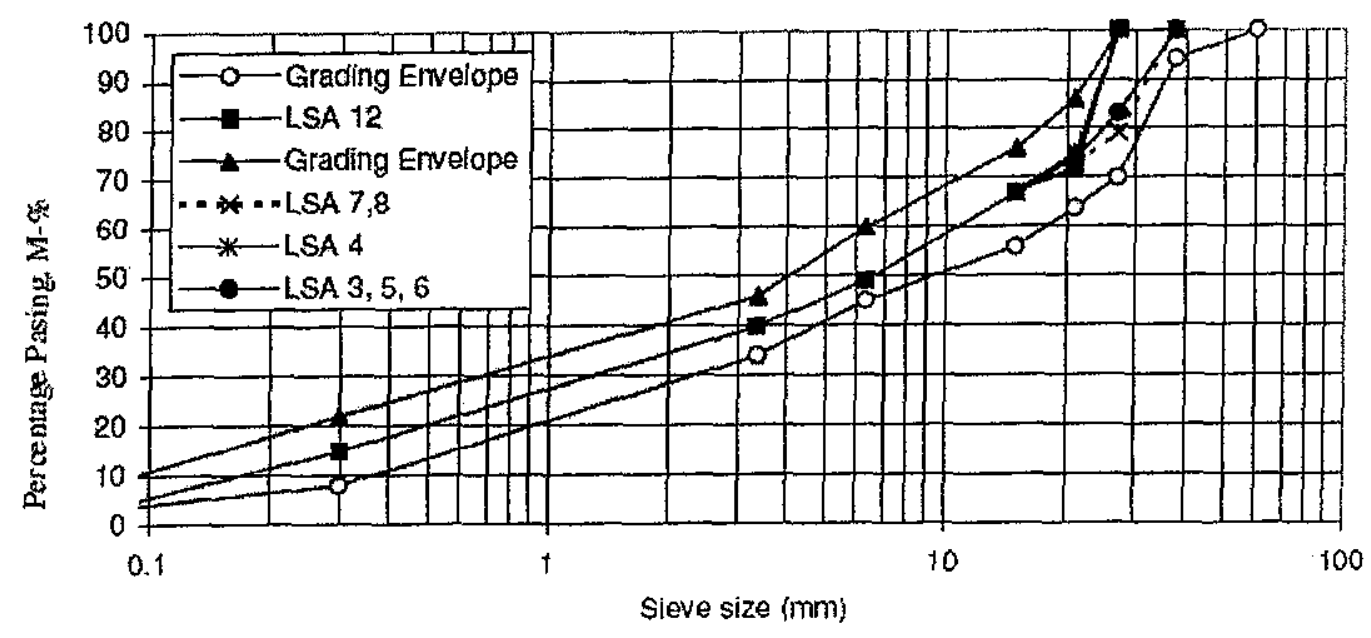

Fig.1:Combined gradings for LSA mix design [1] 
Table 3: Marshall Mix Design

\begin{tabular}{|l|c|c|c|c|}
\hline & LSA-3 & LSA-4 & LSA-8 & LSA-12 \\
\hline Optimum Binder Content & 4.4 & 4.25 & 4.5 & 4.2 \\
\hline $\begin{array}{l}\text { Bulk Specific Gravity at } \\
\text { Optimum Binder Content }\end{array}$ & 2.628 & 2.623 & 2.630 & 2.612 \\
\hline V.I.M. \% & 3.6 & 4.0 & 3 & 4.4 \\
\hline V.M.A. \% & 14.2 & 14.3 & 14 & 14.4 \\
\hline V.F.B. \% & 79 & 75 & 83 & 74 \\
\hline Stability (kgf) & 2000 & 1810 & 2000 & 1966 \\
\hline Flow (mm) & 3.5 & 2.6 & 2.5 & 2.7 \\
\hline
\end{tabular}

There is a modification of the Marshall procedure for large stone sized mixtures by the U.S. Corps of Engineers. The complete aggregate sample is mixed with the asphalt cement and then screened through a 1.0 inch sieve. The portion larger than 1.0 inch is discarded and the balance is used to manufacture samples for the Marshall test in the conventional manner. In consideration of the design criteria, the stability and flow values are left unadjusted; whereas, adjustments are made to the measured voids according to the percentage and specific gravity of the material larger than 1.0 inch diameter.

Pennsylvania DOT, developed procedures for fabricating and testing 6.0 inch diameter samples. They have found that the Marshall stability of a 6.0 inch diameter was at least 1.5 times the stability of 4.0 inch diameter [2].

Several agencies have developed procedure for 2.0 inch maximum stone size mixture where $11.0 \mathrm{lbs}$ of loose mix is compacted by a vibrating hammer in a 6.0 inch diameter mould. The sample is allowed to cool, extruded and then tested for air voids in mineral aggregate.

In the Refusal test developed by the Transport and Road Research Laboratory in the United Kingdom, a compaction standard has been developed. The density of the oven dried core is determined. It is then placed in a 6.0 inch mould and heated to $284^{\circ} \mathrm{F}$. The sample is then compacted to refusal using a 750 watt vibrating hammer for two minutes at each face [3].

A summary of all compaction methods for large stone mixtures is given in Table (4).

\section{b) Proposed New Method}

A 750 watt $50 \mathrm{HZ}$ vibrating hammer with $100 \mathrm{~mm}$ and $145 \mathrm{~mm}$ tamping feet were used in compacting $80 \mathrm{~mm}$ thick asphalt specimen in 6.0 inch diameter mould. This assembly is similar to the one used in the
Refusal test developed by the Transport and Road Research Laboratory in United Kingdom. The mixing and compacting temperatures were determined as per ASTM D-1559. The mixture is then placed in the preheated mold. The $100 \mathrm{~mm}$ tamping foot is moved around the mold giving a few seconds compaction at each of eight equispaced, diametrically opposite positions. The tamping foot is moved from one position to the next before material pushes above its edge. After the required time of continuous compaction, a $145 \mathrm{~mm}$ tamping foot is used to smooth irregularities on the surface of the specimen.

The mold is then turned over; the specimen is pushed down using the $145 \mathrm{~mm}$ tamping foot and compacted for same time as before. After 24 hours, the specimen is removed from the mold.

The specimen is tested for specific gravity as per ASTM D-2726. A $100 \mathrm{~mm}$ diameter core sample is taken from the compacted specimen, which is then tested for stability, flow, indirect strength, and fatigue prediction.

Two asphalt mixtures (LSA-6 and LSA-7) were prepared using vibration method, as follows:

\section{LSA - 6 Mixture}

The aggregate grading of this mix is the same as that of LSA - 3 (Figure-1) different time of vibration ranging from 30 to 240 seconds at different binder contents were used in preparation of the specimens. These samples were then tested for specific gravity as per ASTM D-2726. Figure (2) shows the relation between vibration time and bulk specific gravity.

Each point represents the average of 2 samples. Air voids (VIM) and voids in mineral aggregate (VMA) were then determined at refusal (i.e. at maximum bulk specific gravity of each binder content).

Figures (3) and (4) show the relation between VIM and VMA at refusal with binder content. 
M. El-Shourbagy and S. El-Hamrawy, "Development Of Large Stone Asphalt Mixtures In Riyadh"

Table 4: Compaction procedures for specimen fabrication for heavy duty mixtures [6]

\begin{tabular}{|l|l|c|c|}
\hline \multicolumn{1}{|c|}{ Test Procedure } & Compactive Effort & $\begin{array}{c}\text { Max. Aggregate } \\
\text { Size(inch) }\end{array}$ & $\begin{array}{c}\text { Mold Size Diam. } \\
\text { (inch) }\end{array}$ \\
\hline Marshall & $\begin{array}{l}\text { 75 Blows Each end of Specimen, 10 lb, } \\
\text { Hammer 18" Fall }\end{array}$ & 1.0 & 4.0 \\
\hline $\begin{array}{l}\text { Modified Marshall } \\
\text { Pennsylyania Dot }\end{array}$ & $\begin{array}{l}75 \text { Blows Each end of Specimen, 22.5 lb, } \\
\text { Hammer 18" Fall }\end{array}$ & $1.5-2.0$ & 6.0 \\
\hline $\begin{array}{l}\text { Gyratory Testing } \\
\text { Machine }\end{array}$ & $\begin{array}{l}\text { Car be Adjusted According to Anticipated } \\
\text { Traffic Level }\end{array}$ & $1.0-1.5$ & $4.0-6.0$ \\
\hline TRRL Refusal Test & $\begin{array}{l}\text { Compacted to Refusal 2-4. Using 750 watt, } \\
\text { 50Ez Vibrating Hammer, 4' Tamping Foot }\end{array}$ & $1.5-2.0$ & 6.0 \\
\hline Minnesota Dot & $\begin{array}{l}\text { Vibrating Hammer-30 Secs. Each Face 5 7/8 } \\
\text { Tamping Foot }\end{array}$ & $1.5-2.0$ & 6.0 \\
\hline $\begin{array}{l}\text { California Leading } \\
\text { Compactor }\end{array}$ & $\begin{array}{l}\text { Compacted B7 3.1' 19 Compaction Ram, 20 } \\
\text { Tamping Blows at 250 ps. followed by a static } \\
\text { leveling load }\end{array}$ & 1.0 & 4.0 \\
\hline
\end{tabular}

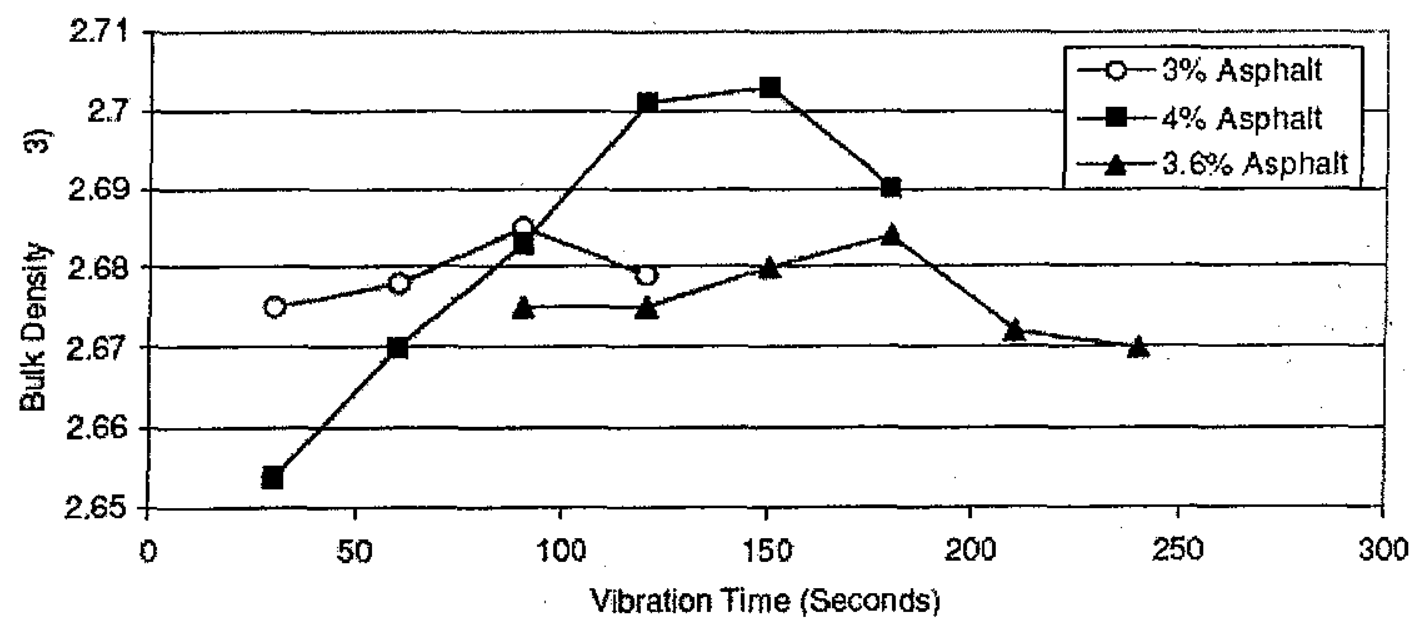

Fig.2: Bulk Density for LSA-6 as a Function of Asphalt Content

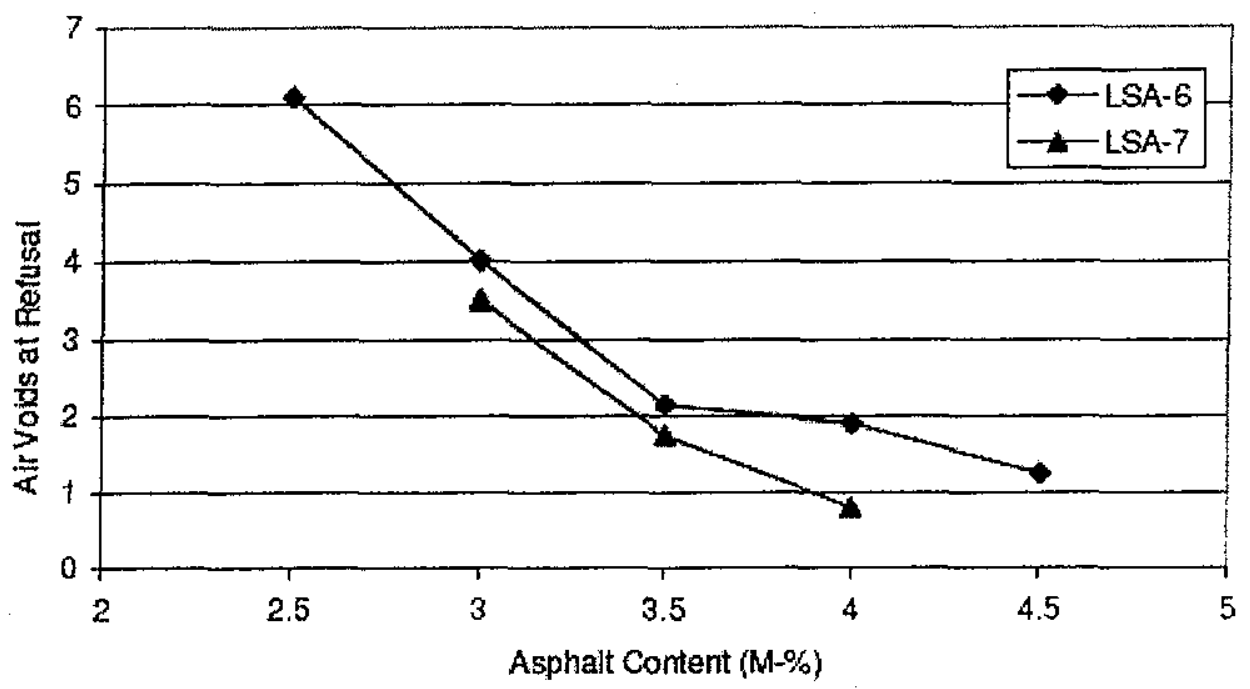

Fig.3: Air Voids at Refusal for LSA-6 \& LSA-7 


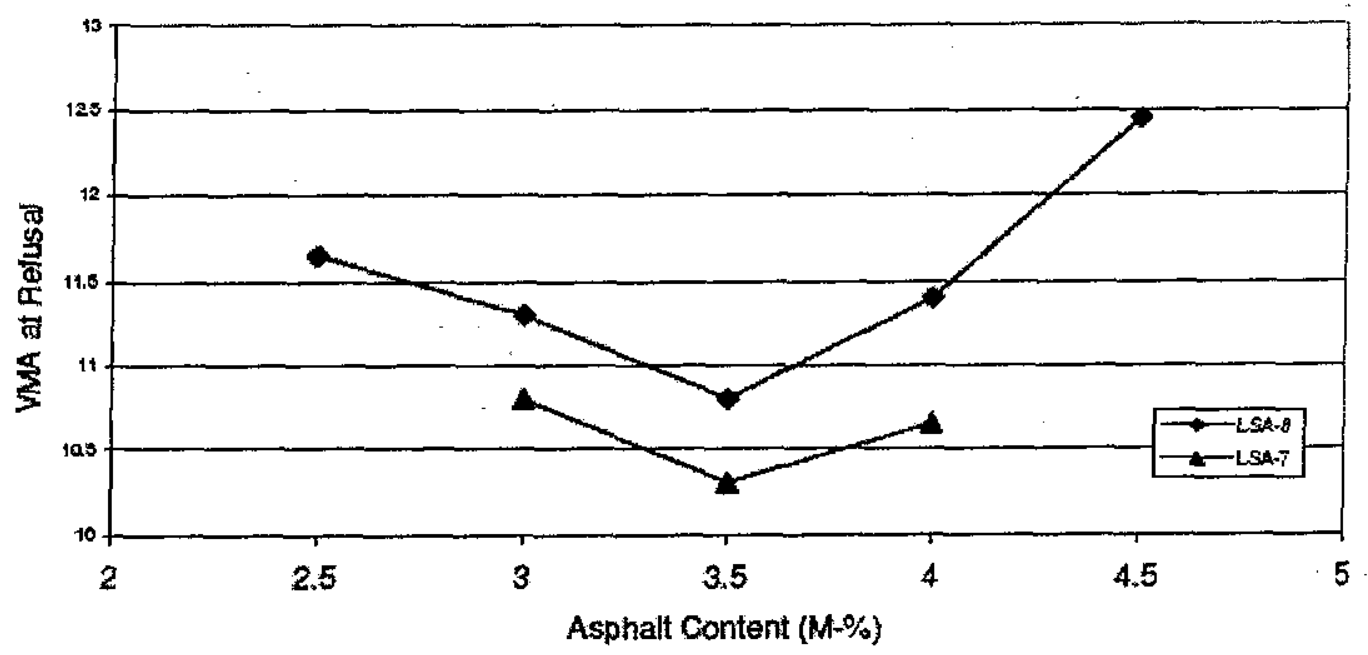

Fig.4: Voids in Mineral Aggregates at Refusal for LSA-6 \& LSA-7

It was considered that air voids at refusal shall not be less than $3 \%$. Therefore, the binder content was selected, putting in mind that VIM at refusal shall be $3 \%$ or more. On the other hand, the time of vibration at the selected binder content was determined, at the point which gives similar bulk specific gravity as that of Marshall Specimen which is compacted at 100 blows per face in Marshall procedure. Table 5 shows the relation between vibration time and bulk specific gravity, flow, stability, voids filled with bitumen (VFB), VMA and VIM at the selected binder content.

\section{LSA - 7 Mixture}

The aggregate grading of this mix is the same as that of LSA -8 (Figure-1). It should be mentioned that the difference between aggregate grading of LSA -6 and LSA -7 is in the percentage retained on sieve $25.4 \mathrm{~mm}$. In grading of LSA -6 , the percent retained on sieve $25.4 \mathrm{~mm}$ is $19 \%$ while it is $23 \%$ in grading of LSA-7 mix. This is in order to examine the effect of increasing the retained on sieve $1.0 \mathrm{inch}$ in both Marshall and vibration method. A similar procedure was followed in LSA - 7 mixes as that of LSA -6 in determining binder content and time of vibration (Table 5).

\subsection{Indirect Tensile Strength}

The ultimate strength of the asphalt mixtures under an indirect tensile stress field was obtained using the indirect tensile testing procedure. The load was applied diametrically at a constant vertical deformation rate of 0.065 inches / minute until reaching the maximum load that the specimens were able to withstand. The maximum load was defined as yield strength. The indirect tensile strength $(\sigma)$ is then calculated using the following equation:

$$
\sigma=\frac{2 P}{\Pi d h}
$$

where:

$$
\begin{array}{lll}
\mathrm{P} & = & \text { maximum load, } \mathrm{lbs} \\
\mathrm{d} & = & \text { specimen diameter, inches } \\
\mathrm{h} & = & \text { specimen thickness, inches }
\end{array}
$$

\subsection{Fatigue Curve Prediction}

$\mathrm{N}_{\mathrm{f}}=\mathrm{k}_{2}\left(\frac{1}{\Sigma}\right)^{\mathrm{n}_{2}}$ The fatigue can be calculated from the following equations (According to Virginia Highway Transportation Research Council).

$\begin{array}{ll}\mathrm{n}_{2} & =0.0374 \sigma-0.744 \\ \log \mathrm{k}_{2} & =7.92-0.122 \sigma\end{array}$

Where:

$\mathrm{Nf}=$ cycles to failure $(\mathrm{a} 1 / 3$ reduction in initial stiffness calculated at approximately 200 cycles).

$\Sigma=$ initial bending strain (based on center point deflection of specimen at approximately 200 cycles).

The chosen values of $\sum$ and corresponding values of calculated $\mathrm{Nf}$ values are then plotted on $\log$ - $\log$ paper. In order to evaluate the indirect tensile strength and fatigue life of both conventional and new mixes, the following evaluation was conducted.

1) Samples of LSA-3, LSA-4, LSA-8 and LSA-12 at optimum binder content using Asphalt Institute mix design were prepared and tested. Other 
samples of LSA-6 and LSA-7 were also prepared at the selected binder content and time of vibration, using new

2) Samples of LSA-3, LSA-4, LSA-8 and LSA-12 at optimum binder content using Asphalt Institute mix design were prepared and tested.

3) Samples of LSA-3, LSA-4, LSA-8 and LSA-12 at optimum binder content using Asphalt Institute mix design were prepared and tested.

4) Other samples of LSA-6 and LSA-7 were also prepared at the selected binder content and time of vibration, using new method of mix design. 4 inch core specimens were taken from 6 inch samples, then tested for indirect tensile strength and fatigue life prediction.

\section{ANALYSIS OF RESULTS}

\subsection{Conventional Mix Design}

Marshall method of mix design as per Asphalt Institute manual MS-2 was used in preparation of LSA-3 and LSA-8. The difference in grading between these two mixes is in the percentage retained on sieve $25.4 \mathrm{~mm}$. In grading of LSA-3 mix, the percent retained on sieve $25.4 \mathrm{~mm}$ is $19 \%$, while it was $23 \%$ in grading of LSA-8.

Table (3) shows optimum binder contents and corresponding properties at these contents. By examining the mix design data of these two mixes, the following comments can be noticed:

1) The variation in bulk specific gravity at same binder content for LSA-8 was higher than that of LSA-3. This was reflected on air voids and VMA values.

2) It is expected that even higher variation in bulk specific gravity, and voids content, will be noticed in plant samples, due to the fact that unequal distribution of aggregate will occur in the 4 inch mould.

3) The institute specific gravity of 6 inch diameter core samples will normally show higher values than the 4 inch laboratory Marshall samples. Therefore, very high degree of compaction will be noticed.

Two other mixes were prepared (LSA-4, LSA-12) in which aggregate larger than $25.4 \mathrm{~mm}$ were substituted with the equivalent weight of 19 $25.4 \mathrm{~mm}$. The optimum binder contents and corresponding properties at these contents are shown in Table (3). The following comments can be said on these mixes:

a) The variation in bulk specific gravity values at same binder content is much less than that of LSA-3 and LSA-8. b) It is very difficult to do this substitution when making Marshall specimens from plant mixes. Therefore, Marshall specimens using laboratory mixes will be different from those made from plant. This will give different values of specific gravity and voids content even at same binder content.

c) The in-situ bulk specific gravity of core specimens, will vary from those of Marshall specimen, because they are of different grading.

d) The mix design does not actually represent the insitu mix.

\subsection{Mix Design by Vibration Method}

Two mixes were prepared (LSA-7) using new method. These 2 mixes have aggregate with same grading as LSA-3 and LSA-8. Table (5) shows comparison between characteristics of large stone mixes by vibration method and by conventional method. The following comments can be mentioned on the large stone mixes, prepared by vibration:

1) The bulk specific gravity values are almost similar for the two methods.

2) The variation in bulk specific gravity at same binder content is low for mixes prepared by vibration. This is due to large molds used.

3) The optimum binder contents of mixes prepared by vibration are lower than those of conventional methods.

4) The VMA and VFB values are lower for mixes prepared by vibration than those prepared by conventional method.

5) The air voids values for mixes prepared by vibration are higher than those prepared by conventional methods.

6) Stability and flow values are close for the two methods.

7) Stiffness

According to shell recommendation, getting bigh Marshall Stability should not be our aim. Also, obtaining the flow and stability requirement separately is not the target. The ratio of stability to flow is important and not their individual values.

This ratio gives a measure of what is termed the stiffness of the mix which can be related to tire pressure. In order to prevent permanent deformation for the mix under high stress the Marshall stability/ flow ratio should not be less than 1.2 times the tire pressure. Shell procedure, for calculating stiffness is shown in Table(5). 
If we consider, the tire pressure to be $150 \mathrm{psi}$, then stiffness should not be less than $1.2 \times 150=180$.

All mixes, which are shown in Table (5) have stiffness higher than 180 . The mix LSA-6 in Table (5) gave the highest stiffness value.

\subsection{Procedure of New Mix Design by Vibration}

The following steps, are proposed to be followed in designing large stone asphalt mixture.

1) The aggregate fractions are combined by different percentage to be within required envelope of grading.

2) By use of vibrating hammer and 6 inches mould, specimens are prepared at different time of vibration and different binder contents.

3) Draw curves, which show relation between bulk specific gravity and time of vibration for different binder contents.

4) Air voids and voids in mineral aggregate at refusal (maximum bulk specific gravity) are determined for each binder content.

5) Draw two graphs showing relation between air voids and VMA at refusal versus binder content.

6) Choose binder content, which gives minimum $3 \%$ of air voids at refusal. This binder content is the optimum.

7) If the Asphalt mixture does not look workable at the selected binder content, then change grading and repeat steps from 1 to 7 .

8) The time of vibration shall be determined, by determining the bulk specific gravity, which corresponds to the average bulk density of three Marshall specimens compacted at 100 blows per face.

\subsection{Indirect Tensile Strength and Fatigue Prediction}

The samples, which were prepared as per clause 4.3 were tested for indirect tensile strength, then fatigue life was predicted according to procedure developed by Virginia Highway Transportation Research Council. Table 6 and Figures 5, 6 and 7 show results of indirect tensile strength and predicted fatigue curves for all these mixes. LSA-6, which was prepared by vibration method, gave highest value of indirect strength.
Figures 5 and 6 show that at low strain values, the fatigue life of LSA-6 and LSA-7 are higher than that of LSA-3 and LSA-8, respectively. However, at higher strain values this trend is changed. This is clear because binder contents of LSA-6 and LSA-7 are lower than that of LSA-3 and LSA-8, respectively.

On the other hand, Figure 7 shows that predicted fatigue life of LSA-4 and LSA-12 are similar at all strain values.

\section{CONCLUSIONS}

Based on the results obtained in this study, the following conclusions could be drawn:

1) New method of mix design which suits aggregate size larger than $25 \mathrm{~mm}$ has been developed by using vibrating hammer and 6 inches diameter mould.

2) This new method is believed to be better than Marshall method in designing large stone mixes. This mould is bigger than the 4 inches Marshall mould, and the vibration is more representative of the way the in situ mix is placed.

3) The binder content as determined by the vibration method is lower than that of Marshall mix design as per Asphalt Institute MS-2.

4) Due to low binder content, and high stiffness values, mixes as designed by vibration method will have better resistance to rutting. Moreover, bleeding will also be avoided, under high large axle loads,

5) The comparison of the new asphalt mixtures as designed by vibration method with those designed by conventional method based upon indirect tensile strength $(\sigma)$ and the fatigue life under constant strain made showed that new mixes have higher tensile strength and acceptable fatigue life.

6) It is strongly recommended to use the maximum theoretical specific gravity in determining degree of compaction rather than Marshall specific gravity.

7) In order to confirm laboratory test results, field trails shall be constructed using mixes designed by vibration methods. Performance of these mixes shall be evaluated with time. 
M. El-Shourbagy and S. El-Hamrawy, "Development Of Large Stone Asphalt Mixtures In Riyadh"

Table 5 : Relation between vibration time and bulk specific gravity, flow, stability, VMA, VFB and VIM at the selected binder content

\begin{tabular}{|c|c|c|c|c|c|c|c|c|c|c|c|c|}
\hline \multirow{2}{*}{$\begin{array}{l}\text { Vibration } \\
\text { Time } \\
\text { (seconds) }\end{array}$} & \multicolumn{2}{|c|}{ Bulk density } & \multicolumn{2}{|c|}{ Air voids } & \multicolumn{2}{|c|}{ VMA } & \multicolumn{2}{|c|}{$\overline{V F B}$} & \multicolumn{2}{|c|}{ Stability } & \multicolumn{2}{|c|}{ Flow } \\
\hline & $\begin{array}{c}\text { LSA- } \\
6\end{array}$ & $\begin{array}{c}\text { LSA- } \\
7\end{array}$ & $\begin{array}{c}\text { LSA- } \\
6\end{array}$ & $\begin{array}{c}\text { LSA- } \\
7\end{array}$ & $\begin{array}{c}\text { LSA- } \\
6\end{array}$ & $\begin{array}{c}\text { LSA- } \\
7 \\
\end{array}$ & $\begin{array}{c}\text { LSA- } \\
6\end{array}$ & $\begin{array}{c}\text { LSA- }- \\
7\end{array}$ & $\begin{array}{c}\text { LSA- } \\
6 \\
\end{array}$ & $\begin{array}{c}\text { LSA- } \\
7\end{array}$ & $\begin{array}{c}\text { LSA- } \\
6\end{array}$ & $\begin{array}{c}\text { LSA- } \\
7\end{array}$ \\
\hline 30 & 2.63 & 2.58 & 5.3 & 7 & 13.8 & 13 & 66 & 55 & 1.5 & 1.5 & 3.0 & 4.7 \\
\hline 60 & 2.65 & 2.64 & 4.3 & 5.5 & 12.7 & 12.4 & 71 & 63 & 2.7 & 1.5 & 3.4 & 3.7 \\
\hline 90 & 2.68 & 2.66 & 3.2 & 4.6 & 11.8 & 11.6 & 77 & 67 & 2 & 1.75 & 4.4 & 3.8 \\
\hline 120 & 2.69 & 2.665 & & 4.5 & 11.55 & 11.65 & 79 & 68 & 2.4 & 2.45 & 3.6 & 3.65 \\
\hline 150 & 2.7 & 2.69 & 2.5 & 3.5 & 11 & 10.7 & 84 & 73 & 1.8 & 2.65 & 2.7 & 3.4 \\
\hline 180 & 2.71 & 2.66 & 2.1 & 4.5 & 10.7 & 11.6 & 86 & 67.5 & 2.4 & 2.2 & 4.2 & 4.2 \\
\hline 210 & 2.705 & 2.685 & 2.4 & 3.6 & 10.8 & 10.7 & 85 & 72.5 & 2 & 2.4 & 3.8 & 3.8 \\
\hline
\end{tabular}

Table 6 :Indirect tensile strength and fatigue parameters

\begin{tabular}{|c|c|c|c|c|c|c|}
\hline Type of Mix & $\begin{array}{c}\text { Retained of } \\
\text { Sieve 25.4mm }\end{array}$ & $\begin{array}{c}\text { Method of Mix } \\
\text { Design }\end{array}$ & By PS1 & N2 & Log K2 & K2 \\
\hline LSA 3 & 191 & Conventional & 133 & 4.23 & -8.306 & $4.94 \sum-09$ \\
\hline${ }^{*}$ LSA 6 & 191 & Vibration & 206 & 6.96 & -17.212 & $6.14 \sum-18$ \\
\hline LSA 8 & 231 & Conventional & 144 & 4.64 & -9.648 & $2.25 \sum-10$ \\
\hline * LSA 7 & 231 & Vibration & 181 & 6.03 & -14.162 & $6.89 \sum-15$ \\
\hline LSA 4 & Zero & Conventional & 174 & 5.76 & -13.308 & $4.92 \sum-14$ \\
\hline LSA 12 & Zero & Conventional & 188 & 6.29 & -15.016 & $9.64 \sum-16$ \\
\hline
\end{tabular}

* Inches core samples were taken from 6 inches specimens then tested for indirect tensile strength.

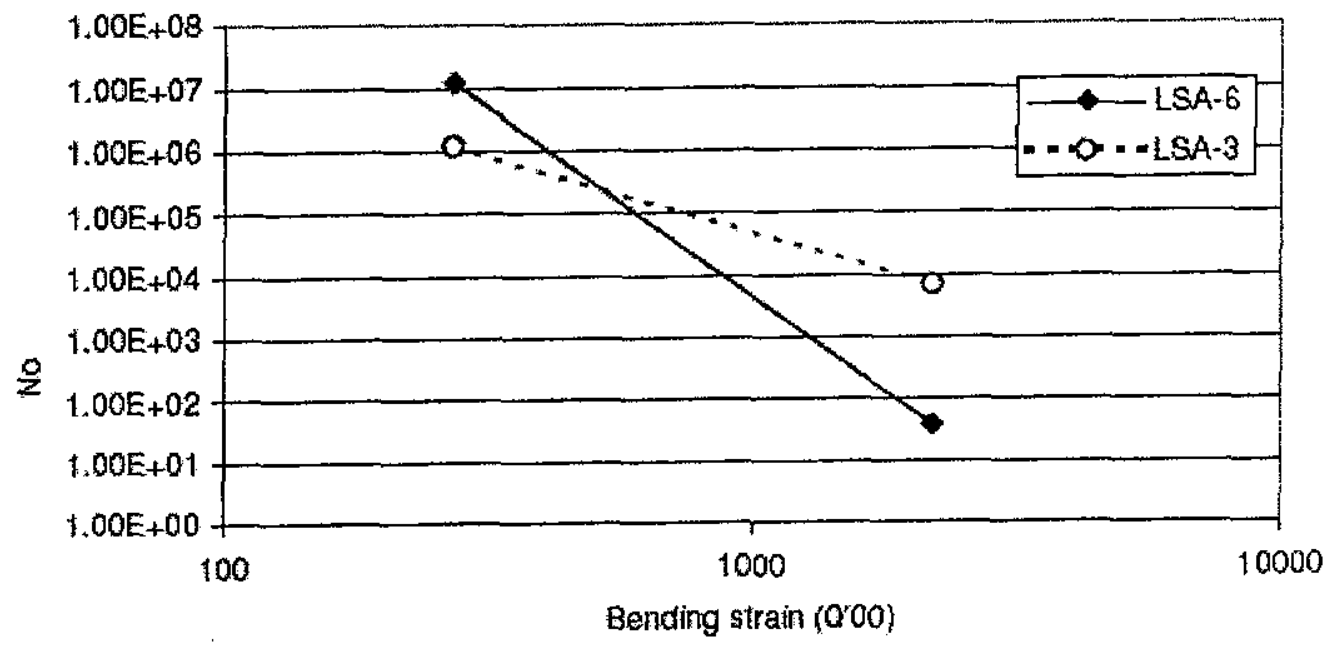

Fig.5:Prediction fatigue curve for LSA-3 \& LSA-6 


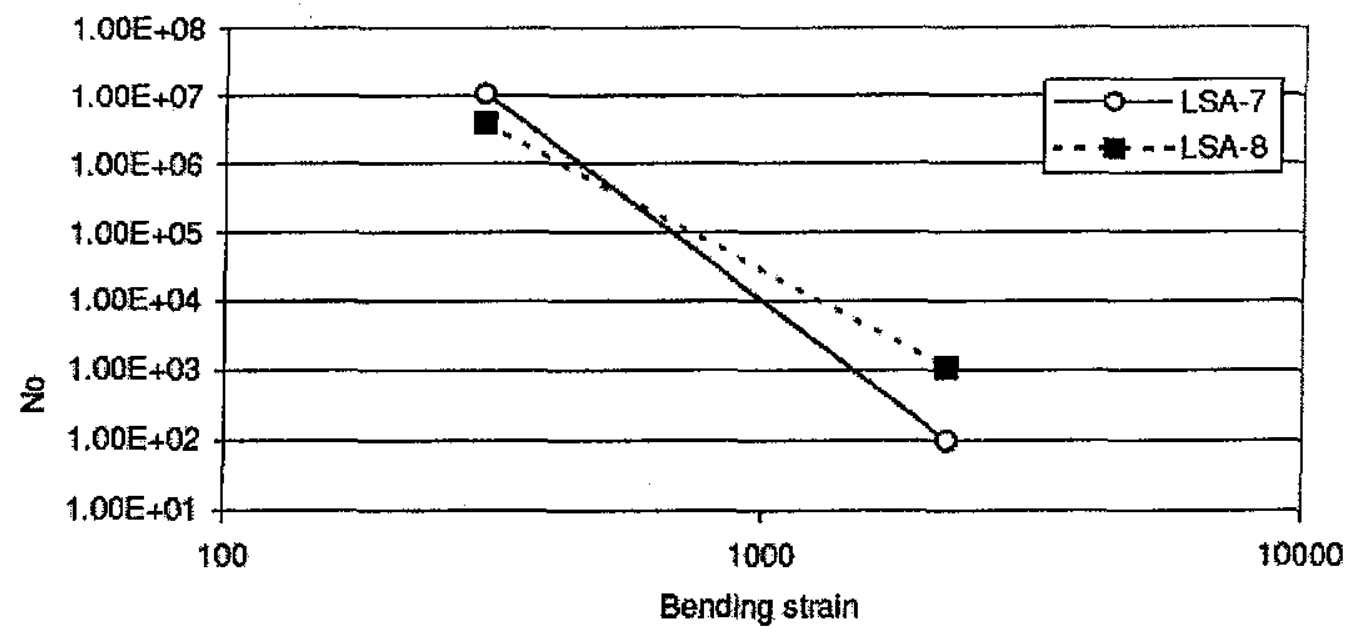

Fig.6: Predicted fatigue curve for LSA-8 and LSA-7

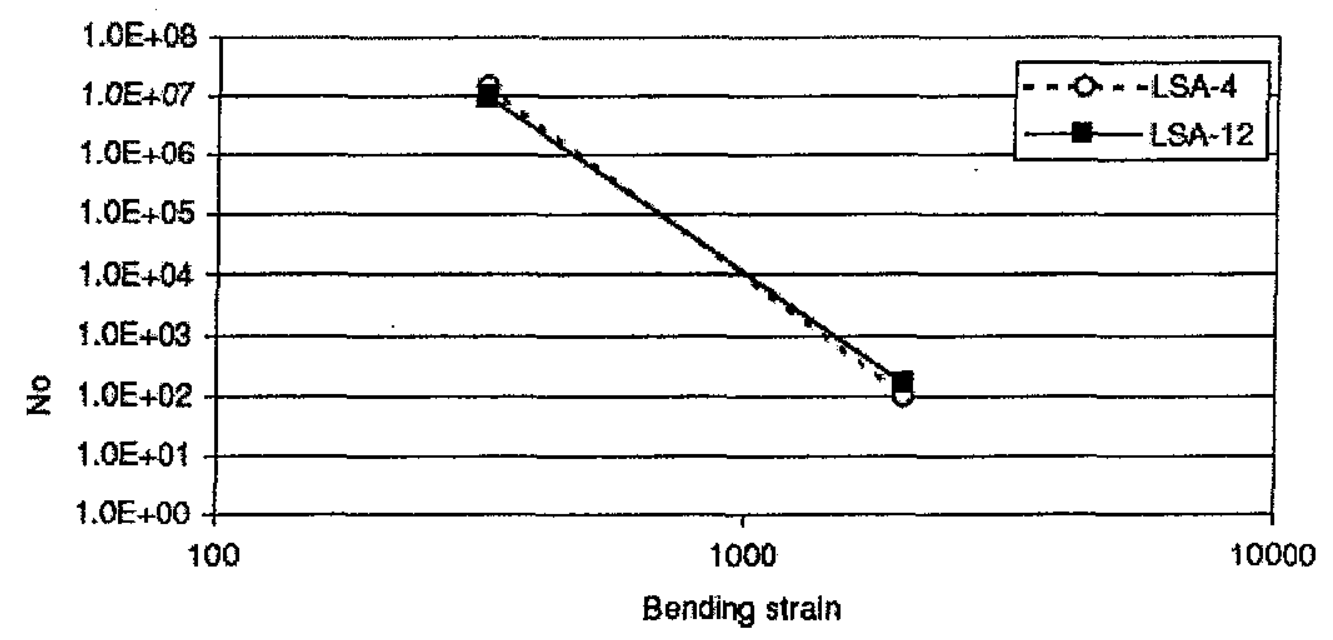

Fig.7: Prediction fatigue curve for LSA-4 and LSA-12

\section{REFERENCES}

[1] Acott, M. "The design of Hot Mix Asphalt for Heavy Duty Pavements" National Pavement Association, Riverdale, Maryland.

[2] Acott, M. "Today's Traffic Calls for Heavy Duty Asphalt Mixes". National Asphalt Pavement Association, Riverdale, Maryland.

[3] "Design and Performance Study of a Heavy Duty Large Stone Hot Mix Asphalt under Concentrated Punching Shear Conditions". National Asphalt Pavement Association, Riverdale, Maryland.

[4] Kandhal, P.S., and Mallick. R.B., "Effect of Mix Gradation on Rutting Potential of Dense-Graded Asphalt Mixtures", Transportation Research Record \#1767, TRB, National Research Council, Washington, D.C., 2001.
[5] Powell, W. D., "Standards for Compaction of Dense Road base Macadam". Transport and Road Research Laboratory, Crowthome, Berkshire, 1982.

[6] Ramsey, S. "The Percentage Refusal Density Test". The Journal of the Institution of Highways and Transportation, February 1985.

[7] McNical, A., and Bell, G., "Air Voids Versus Prd." The Journal of the Institution of the Institution of Highways and Transportation", February 1986. 